\title{
Designing mathematical-technological activities for teachers using the Technology Acceptance Model
}

\author{
Gerrit Stols \\ University of Pretoria \\ Email: gerrit.stols@up.ac.za
}

\begin{abstract}
The objective of this study was the design and development of mathematical technological activities. The guiding model in developing these activities was the Technology Acceptance Model (TAM). The two main issues to address, according to the model, are the "perceived ease of use" and the "perceived usefulness" of the software. The activities were used, refined and tested in a professional development programme which consisted of five hands-on laboratory sessions, lasting 2 hours each, spaced over a 3month period. The study found that the approach of letting teachers experience technology while engaged in authentic mathematical tasks promotes the perceived usefulness of Geometer's Sketchpad (GSP) by the teachers. At the end of the series of workshops, $91 \%$ of the teachers indicated in the summative evaluation that these workshops helped them to understand geometry better. This finding was supported by the $21.5 \%$ increase in the pre-test and post-test average score.
\end{abstract}

\section{Background \& theoretical framework}

Computers play an important role in the daily lives of learners and teachers. Although the power of computers and software is increasing, we are not seeing the impact of this in our classrooms. Even when computers are available, teachers do not use them as expected (Vrasidas \& Glass, 2005). Although the use of technology does not guarantee effective learning, some aspects of technology make it easier to create learning environments that are in line with the principles of learning (Bransford, Brown \& Cocking, 1999). For example, it is possible to make complicated subjects like geometry more accessible with the aid of technology by using new approaches to visualisation and analysis through animation, and other techniques that tap the multiple intelligences of the learners (Bransford et al., 1999). According to Bransford et al., the new technologies can help learners to visualise difficult-to-understand concepts and help to create an active problem-solving environment. But despite all the possible advantages, teachers in general do not make use of these technologies.

Salomon (2005) believes that what is needed is better teacher preparation. Wenglinsky (1998: 33) also emphasises the importance of preparing teachers to use technology by stating: "[T]he study suggests that federal and state policymakers should redouble their efforts to ensure that teachers are properly trained to use computers." Teacher preparation and professional development opportunities play a crucial role in helping teachers to use technology for these reform-oriented purposes (Willis \& Mehlinger, 1996). But teacher preparation, according to Salomon (2005: xvii), is a long process that requires first-hand learning by experience, active doing and deep reflection. This implies the development of activities for teachers. The question, however, is what kind of activities can be used in teacher preparation programmes that will increase the possibility that the teachers themselves will use technology in their own classrooms. A model that can guide us in this process is the Technology Acceptance Model (TAM).

Fred Davis and Richard Bagozzi developed the Technology Acceptance Model (TAM) as an attempt to explain factors that influence computer users' decisions about how and when they will use it. TAM is a general model that predicts and explains user acceptance of information technology systems. TAM postulates that an individual's attitude towards technology and behavioural intention to use it is determined by the perceived usefulness and perceived ease of use of that specific technology (Davis, 1989; Venkatesh \& Davis, 2000). According to this model, there is a strong causal link between intention and actual behaviour. Sheppard, Hartwick and Warsaw (1988) found a correlation of 0.54 in their study between behavioural intention and actual use. In the context of teachers' professional development, "perceived usefulness" is about the extent to which a teacher believes that the use of technology - in this case Geometer's Sketchpad (GSP) - will enhance his or her own understanding or will enhance the teaching/learning process. "Perceived 


\section{Gerrit Stols}

ease of use" is about teachers' belief that using the specific technology Geometer's Sketchpad will be free of effort. Hu, Clark and Ma (2003) used the Technology Acceptance Model (TAM) to examine the use of PowerPoint by school teachers. They found that there is a significant influence path from job relevance to perceived usefulness and finally user acceptance. Although perceived ease of use of technology did not directly affect user acceptance, it did via perceived usefulness. This implies that a teacher will not use a technology just because it is easy to use, but perceived difficulty may prevent him or her from using a technology. We can therefore conclude that the TAM may also be used in the context of teachers' technological professional development.

\section{Designing principles of the activities}

The target population of this study was in-service teachers of grade 11 and 12 South African mathematics. In order to address the grade 11 and 12 teachers' perceptions of the usefulness of Geometer's Sketchpad (GSP) in school geometry, the South African school-geometry curriculum was used as a basis for the development of the activities. Vrasidas and Glass (2005) expressed the view that teachers should not be taught out of context. According to these authors the best way to prepare teachers is to use technology while working on meaningful tasks. The activities must be of such a nature that teachers experience technology while engaged in authentic mathematical tasks. Garofalo, Drier, Harper, Timmerman, and Shockey (2000) devised a set of guidelines to be used when developing mathematical activities and materials. Two of the guidelines will help to increase the perceived usefulness of the technology by the teachers: worthwhile mathematics must be addressed, and the activities must take advantage of technology.

It is, however, important at this point to remember that the introduction of technology will not in itself improve the quality of education. A lot depends on how we use it. Wenglinsky (1998) examined data obtained from the 1996 National Assessment of Educational Progress in an attempt to determine the relationship between computer use and students' achievements in mathematics. This research emphasises the importance of professional development, and of the development of higher order thinking skills:

Professional development and higherorder thinking are both positively related to academic achievement: Students with teachers who have had such professional development show higher levels of achievement, as do those who are taught higher-order skills with computers (Wenglinsky, 1998: 28-29).

The aim was therefore to develop higher order thinking skills in the context of high school geometry problems. This is in line with findings reported in literature. For example, it has been argued that the most successful technology-based projects used content and instructional approaches compatible with the local curriculum (Zhao, Pugh, Sheldon \& Byers, 2002). Further, Wenglinsky (1988) has also pointed out that the use of technology must focus on the development of higher order thinking skills. While working on the activities the teachers must experience the usefulness of the technology for themselves.

\section{Choosing software}

One of the reasons why teachers are reluctant to use technology for instruction is that they believe it will take more time (Vrasidas and Glass, 2005). Teachers indicated that they do not have the time to learn how to use computers themselves and then to pass that knowledge on to the learners. Vrasidas and Glass (2005: 3) state, "In 1999 the most frequently reported obstacles to the use of computers and the Internet in the classroom by public school teachers were lack of released time for teachers to learn how to use computers". To address this problem it is important that the technology used for professional development is easy to use and does not take too much time and effort to master. This is also important from the perspective of TAM because the behavioural intention of teachers to use technology is determined by the perceived usefulness and perceived ease of use.

Technological applications have their own advantages and constraints and therefore some software is better suited to particular parts of the curriculum than other software programs. It is important that the software should fit the planned activities. Vessey and Galletta (1991) explain that cognitive fit is a "cost benefit characteristic that suggests that, for most effective and efficient problem-solving to occur, the problem representation and any tools or aids should all support the strategies (methods or processes) required to perform that task".

According to Russell, Bebell, O'Dwyer, and O'Connor (2003), it seems prudent to focus teacher preparation on a specific technology, in depth, rather than adopt a more general approach. The instructional objective with graphing software, 
according to Wong (1998), is to develop and reinforce concepts, to rectify common errors, to check graphical solutions, to solve equations graphically, to test conjectures through problemposing, to encourage users to become metacognitive, to help users to acquire information technology skills and to enhance the desire to learn. Geometer's Sketchpad (GSP) can help enhance some of the essential skills for teaching mathematics. Sanders (1998) comments that the appropriate use of GSP can enhance mathematics teaching, improve conceptual development and visualisation, and create opportunities for creative thinking. In this study GSP was used because it is an easy program to learn, but also a powerful tool for the development of geometrical understanding. The software prompts the user to undertake mathematical investigations and can be used for exploration, discovery and problem-solving.

GSP was originally designed for teaching geometry in secondary schools. It includes the classical ruler and compass constructions. The program allows teachers and learners to work quickly through numerous examples (by dragging) and enables them to discover patterns, to explore and to test conjectures by constructing their own sketches. The latest version of GSP has a number of trigonometric and algebraic features, which enable teachers and learners to find relationships between symbolic and graphic representations.

\section{Designed activities}

The activities start with a high level of guidance on how to use GSP in order to help the teachers to perceive GSP as an easy program to use. Mishra and Koehler's (2006) approach to the introduction of technology was followed. They believed that the teachers should learn about technology as and when necessary to complete their tasks. While working through the activities using GSP, they also learned how to use the software. It was therefore important to choose activities that would cover all the basic functions of GSP. Although the aim of the series of workshops was the development of higher order thinking, the activities start with basic discovery in order to help the teachers to learn how to use the basic functions of the software. In summary, the activities have been designed in such a way that the level of mathematical thinking increases (from basic discoveries to advanced problem-solving) while the technology guidance gradually decreases (see Figure 1).

\section{Examples of activities}

In the first activity the mathematical thinking level is low (basic discovery) but there is a high level of technological guidance.

\section{Activity 1}

Construct a cyclic quadrilateral ABCD. Measure the sum of the opposite interior angles. Drag points A, B, C and D. Does the sum stay the same? You can do the activity using the following steps:

Step 1: Click on the GSP icon 3 . The following screen will appear (see Figure 2).

Step 2: Select the compass tool $\odot$ and construct a circle.

Step 3: Select the point tool $\stackrel{+}{-}$ and construct four points on the circumference of the circle.

Step 4: Select the text tool $\mathbf{A}$ and click on the four constructed points to label them A, B, C and D.

Step 5: Select the straight-edge tool and construct the four segments $\mathrm{AB}, \mathrm{BC}, \mathrm{CD}$ and DA (see Figure 3).

Step 6: Select the selection arrow tool and mark points A, B and C. (The points will be highlighted.) Select "Measure" on the Menu toolbar (see Figure 4). Click "Angle" and the measure of $\angle \mathrm{ABC}$ will appear: $\mathrm{m} \angle \mathrm{ABC}=97.46^{\circ}$. Measure $\angle \mathrm{BCD}, \angle \mathrm{CDA}$ and $\angle \mathrm{BAD}$ in the same way.

Step 7: To calculate the sum of the opposite angles, click on the "Measure" toolbar and choose "calculate" from the toolbar. The following will appear: "Click: $\mathrm{m} \angle \mathrm{ABC},+$, $\mathrm{m} \angle \mathrm{ADC}$, OK". The sum of $\angle \mathrm{ABC}$ and $\angle \mathrm{ADC}$ will appear.

Step 8: Drag the different points. Does the measure of the angles stay the same? What about the sum of the interior opposite angles?

\section{Activity 3}

Use GSP to convince learners that the line joining the mid-points of two sides of a triangle is parallel to the third side and equal to half the third side. How do you determine if two lines are parallel?

The following activity was included because it requires and helps develop a high level of technological skills, while it still only requires a low level of mathematical thinking skills 


\section{Gerrit Stols}

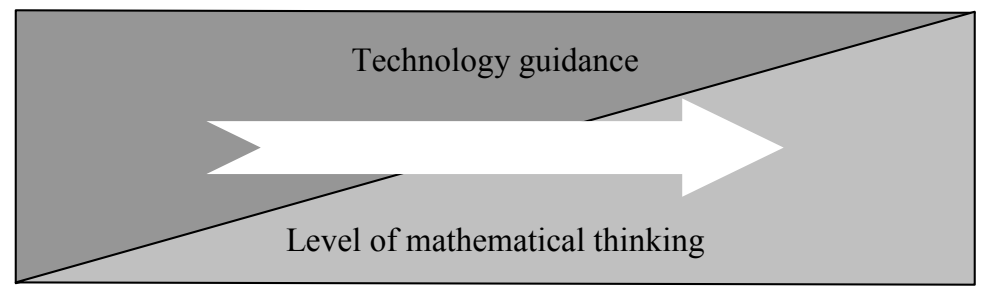

Figure 1. Model for designing activities

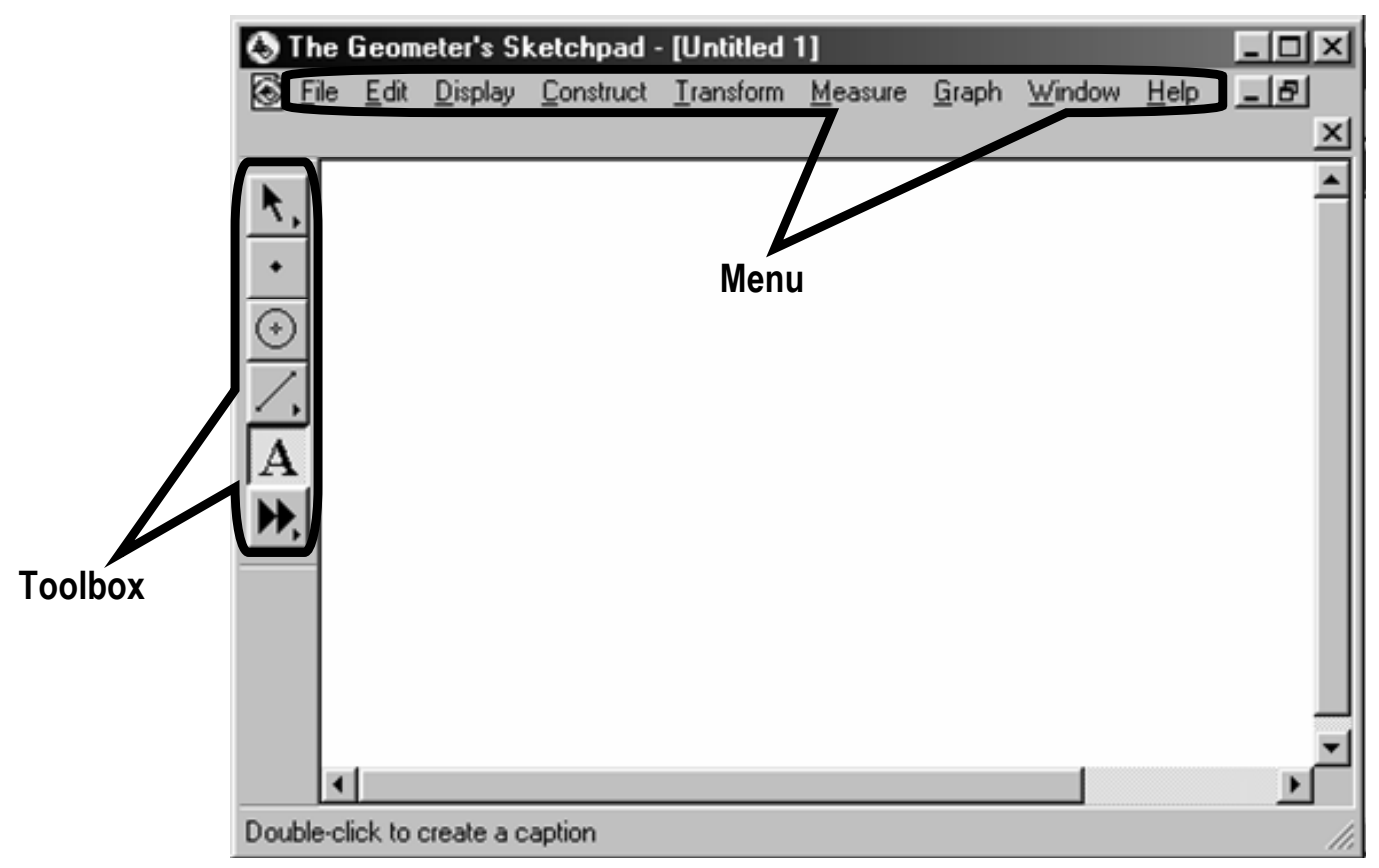

Figure 2. GSP Interface

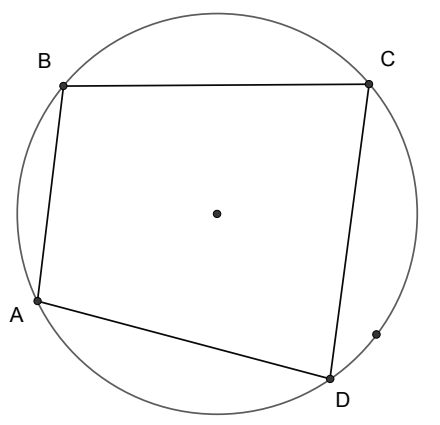

Figure 3 . The result of step 5

\section{File Edit Display Construct Iransform Measure Graph Window Help}

Figure 4. Menu toolbar 
(knowledge). It is an advanced discovery activity. The purpose of the activity was to enable the teachers to use as many different functions and features of GSP as possible. It helped the author to assess the teachers' competence in the use of the different functions of GSP. The group discussed the definitions of the incentre, circumcentre, orthocentre and centroid of a triangle before they started with the activity.

\section{Activity 9}

Three of the four points of concurrency associated with triangles are the incentre, circumcentre, orthocentre and centroid. Three of them are on the same line. The line is called the Euler line. The Euler line is named after Leonard Euler, who proved that these three points of concurrency are collinear. Construct the Euler line of a triangle. Which point of concurrency is not on the Euler line? Use the drag test to see if this is always true.

The successful completion of activity 9 indicates the ability to use the software. It was therefore important to allow enough time for all the teachers to complete this activity successfully. After this the focus shifts to the development of mathematical thinking skills. For example, activities 10 and 12 require more mathematical thinking skills than computer skills:

\section{Activity 10}

What is the sum of the measures of the 100 interior angles of a 100-gon (a triangle is a 3-gon)? How did you solve the problem?

\section{Activity 12}

If you have a piece of land that is a quadrilateral, what kind of quadrilateral will be formed if you take the midpoint of each of its four sides and join these midpoints? Use GSP to prove your belief. Explain mathematically why this will always be true.

To increase the level of the perceived usefulness of GSP, the activities stimulated the teachers to think and reflect in terms of their own classroom practice and to reflect on the value of using GSP to convince their learners of the truth of the geometry theorems. This was, for example, the aim of activities 17 and 30. It is important to note that the discovery of a conjecture, although convincing because of the drag-test, does not replace formal mathematical proofs.

\section{Activity 17}

Use GSP to convince the learners of the truth of the following grade 10 theorems:

- Triangles on the same base (or on equal bases) and between the same parallel lines are equal in area.

- Parallelograms on the same base (or on equal bases) and on the same side of the base are equal in area if they lie between the same parallels.

\section{Activity 30}

a) Use the following school geometry theorems and use GSP to convince the learners that they are true (that is inductive reasoning).

b) Prove these theorems using deductive reasoning:

- If a line is drawn parallel from one side of a triangle, it will divide the other two sides proportionally.

- If a line divides two sides of a triangle in the same proportion, then that line is parallel to the third side.

The most difficult activity in terms of mathematical thinking according to the teachers was activity 36 . Solving this activity requires doing mathematics and using higher order reasoning. GSP could only help the teachers to understand the problem, but did not help them in solving it.

\section{Activity 36}

Divide the area of $\triangle \mathrm{ABC}$ (see Figure 5) into three equal parts by drawing two lines parallel to $\mathrm{BC}$. What is the ratio of AK:KL:LB? Explain mathematically why the ratio divides the area of $\triangle \mathrm{ABC}$ into three equal parts.

Extension problems were also given to challenge the more able teachers. They were asked to develop their own geometry and analytical geometry questions using GSP. In addition to the activities, the workshop manual contains reflective

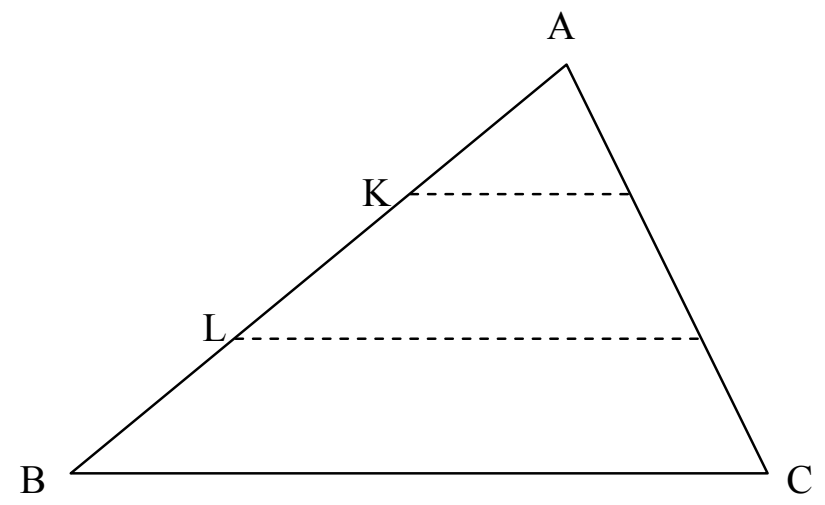

Figure 5. Triangle $A B C$ 


\section{Gerrit Stols}

questions to help the teachers to reflect on the usefulness of GSP in their own teaching when they reach the end of each workshop.

\section{Methodology}

Data for the study were drawn from a series of five two-hour workshops that were conducted by the author over a period of three months. The participants were 15 teachers from previously disadvantaged schools in the Pretoria region in South Africa. All of them were grade 11 and 12 geometry teachers. All the teachers had taught mathematics in previously disadvantaged rural schools. The local Department of Education selected the participants. Of the 15 original participants, 12 completed the series of five workshops. The reason for non-completion of the series of workshops by three participants was an inadequate level of computer literacy. In the first questionnaire, the teachers had to indicate their level of computer literacy. The following data were collected on the computer background of the 15 teachers:

- 2 of the 15 teachers have an e-mail address.

- 14 of the 15 teachers have computers at school.

- 8 of the 15 teachers have computers at home.

- 9 of the 15 have computer labs at school.

- 1 of the 15 has access to the Internet at home.

- 7 of the 15 use word processors for school work.

One teacher indicated that he was not computer literate; there were also three beginner computer users, nine novice users and two expert users. The non-computer literate teacher and two of the three beginner users failed to complete the program. This suggests that non-computer literate and beginner users first need to complete a general computer skills training session before they can enrol for such a program. This essentially entails being able to use a mouse, open files, save files, copy and paste, etc.

\section{Data collection procedure}

The teachers completed questionnaires during and after each workshop and were asked to keep a reflective journal. The reflective journals provided us with documentation of a continuous cycle of enquiry. In addition to the journals, data were gathered to assess the impact of the workshops. At both the beginning and the end of each series of workshops, the teachers completed the same test. The test comprised questions similar to the grade 12 second paper examination questions. Further information was obtained from teachers' journal entries, workshop evaluations completed at the end of each workshop, a summative evaluation questionnaire and interviews. Two of the teachers were interviewed after the last three workshops.

A pilot study was conducted with one teachera fully computer literate teacher. The purpose of the pilot study was threefold, namely to:

- Follow the change and growth in the teacher's conceptual development and understanding of mathematics.

- Develop and refine training materials (teachers' worksheets and notes).

- Determine the effective duration and nature of a full basic course for GSP teachers.

The developed and refined materials from the pilot study were used in a workshop for 15 teachers with different levels of computer literacy. A series of five two-hour workshops were conducted.

\section{Results}

Although 10 out of the 15 teachers are positive about geometry, they find it difficult to teach geometry. When asked to write about their experience of teaching geometry and their beliefs about learning geometry, they had the following to say:

- 7 out of 15: Teaching geometry is a nightmare /difficult/hell.

- 5 out of 15: Learners have negative attitudes.

- 1 out of 15: Learners find it difficult.

- 1 out of 15: Learners must learn theorems and practice geometry.

- 1 out of 15: Learners like to experience things. The feedback indicated that the respondents were confident about teaching geometry after attending the workshops. The teachers agree (with 9 of the 12 strongly agreeing) that workshops helped to increase their levels of confidence. Some of the feedback included the following:

I will try to open afternoon classes in the computer laboratory for my pupils so that I can give them more attention to improve their geometry.

Learners are more enthusiastic about maths. They work more problems than usual.

The learners will be very positive in doing geometry unlike the situation that we are having at our schools where they are negative.

At the end of the series of workshops, 11 of the 12 teachers indicated in the summative evaluation that the workshops helped them to understand geometry better. The most useful part was using Geometer's Sketchpad (GSP) to design riders, 
which was the purpose of the fifth workshop. In this regard, feedback included statements such as:

I had a problem before but now I think I will approach it (geometry) with confidence.

After this workshop I think I have gained confidence in geometry teaching and I'm having a positive attitude.

When I came here I had a very negative attitude as learners did not really understand geometry, but now I am positive that I will also change the learners' attitude toward geometry.

Although the teachers were not allowed to use GSP during the pre- and post-test the teachers' pretest and post-test results showed a 21.5\% improvement. The same tests were used. The average marks were $54.8 \%$ for the pre-test and $76.3 \%$ for the post-test. The teachers' ability to answer the questions improved in all the questions.

Eighty-three percent of the teachers find that GSP is an easy program to use. All the teachers believe that the use of GSP in schools will help learners, and 11 of the 12 believe that it is possible to use GSP in schools. The same 11 teachers also believe that learners will be able to learn to use the software. In the summative evaluation 9 out of 12 of the teachers believed that it is not possible to teach geometry successfully without using technology.

\section{Discussion, implications and limitations}

Looking at the results from the perspective of the TAM, the teachers perceived Geometer's Sketchpad (GSP) to be extremely useful. The approach of integrating the development of computer skills with geometric discovery has proved to be successful. Future workshops must include more group discussions on pedagogical issues. The focus of these workshops was on conceptual development, problem-solving and mastering the software. From the videos and interviews it is clear that the teachers demonstrate conceptual understanding. They interpret mathematical principles in a problem and translate those ideas into a coherent mathematical representation using the important facts of the problem. Teachers show good conceptual understanding of the geometry and choose appropriate representations. From the perspective of the TAM the two main factors that determine an individual's intention to use a technology are "perceived usefulness" and "perceived ease of use". Given the strong causal link between intention and actual behaviour we can conclude therefore that these teachers would use GSP in their classrooms to teach geometry if it was possible for them to do so.

The teachers who attend these workshops are very positive and want to learn more. The responses and evaluations after each workshop show that the teachers want more and longer workshops. All of them agree (with 9 out of 12 indicating that they strongly agree) that they would gladly attend similar workshops in future. GSP often requires teachers to rethink their teaching practice.

In the South African context, the perceived usefulness was dangerously high. The implication of the fact that 9 out of 12 of the teachers believe that it is not possible to teach geometry successfully without using GSP is that they have a valid excuse for not teaching geometry effectively in their own schools because the teachers who attended this series of workshops were all from previously disadvantaged schools and not all of the schools have computer labs. Sixty percent of the teachers indicated that they have computer labs at their schools, with an average of 17.6 computers per lab. This figure may look impressive for a Third World country, but the computers are normally old computers. The majority of these schools can also not afford to buy a site licence for GSP.

One way to address the problem in future is to spend time with the teachers after the computer sessions to assist them in developing similar pen and paper or folding activities that do not require the use of a computer to give them a more realistic view of the use of technology. More research is needed to determine the impact of a high "perceived ease of use" of technology on the part of teachers who do not have, or cannot afford, the technology. Without knowing the full picture, using technology could do more harm than good. A possible future teaching sequence could, for example, consist of manual explorations, followed by computer explorations and then manual explorations again.

\section{References}

Bransford, J., Brown, A. \& Cocking, R. (1999). How people learn. Washington, DC: National Academy Press.

Davis, F.D. (1989). Perceived usefulness, perceived ease of use, and user acceptance of information technology. MIS Quarterly, 13(3), 319-340. 


\section{Gerrit Stols}

Garofalo, J., Drier, H., Harper, S., Timmerman, M.A. \& Shockey, T. (2000). Promoting appropriate uses of technology in mathematics teacher preparation. Contemporary Issues in Technology and Teacher Education, 1(1), 6688.

Hu, P.J., Clark, T.H. \& Ma, W.W. (2003). Examining technology acceptance by school teachers: a longitudinal study. Information Management, 41(2), 227-241.

Mishra, P. \& Koehler, M. J. (2006). Technological pedagogical content knowledge: A framework for teacher knowledge. Teachers College Record, 108(6), 1017-1054.

Russell, M., Bebell, D., O’Dwyer, L. \& O’Connor, K. (2003). Examining Teacher Technology Use: Implications for preservice and inservice teacher preparation. Journal of Teacher Education, 54(4), 297-310.

Salomon, G. (2005). Preface. In C. Vrasidas \& G.V. Glass (Eds.), Preparing Teachers to Teach with Technology: Current Perspectives on Applied Information Technologies (pp. xvxviii). Greenwich: Information Age Publishers.

Sanders, C.V. (1998). Geometric constructions: visualizing and understanding geometry. Mathematics Teacher, 91(7), 554-556.

Sheppard, B.H., Hartwick, J. \& Warsaw, P.R. (1988). The theory of reasoned action: A metaanalysis of past research with recommendation for modifications and future research. Journal of Consumer Research, 15, 325-343.
Venkatesh, V. \& Davis, F.D. (2000). A theoretical extension of the technology acceptance model: Four longitudinal field studies. Management Science, 46(2), 186-204.

Vessey, I. \& Galletta, D. (1991). Cognitive fit: An empirical study of information acquisition. Information Systems Research, 2(1), 63-86.

Vrasidas, C. \& Glass, G.V. (Eds.) (2005). Preparing Teachers to Teach with Technology: Current Perspectives on Applied Information Technologies. Greenwich: Information Age Publishers.

Wenglinsky, H. (1998). Does It Compute? The relationship between educational technology and student achievement in mathematics. Princeton: Educational Testing Service.

Willis, J. \& Mehlinger, H. (1996). Information technology and teacher education. In J. Sikula, T.J. Butter \& E. Guyton (Eds.), Handbook on research in teacher education (pp 978-1029). New York: Simon \& Schuster Macmillan.

Wong, K.Y. (1998). Graphing software: computers for mathematics instruction (CMI) project. Retrieved June 25, 2004, from http://academic.sun.ac.za/mathed/software/grap hmat.pdf

Zhao, Y., Pugh, K., Sheldon, S., \& Byers, J. (2002). Conditions for classroom technology innovations: executive summary. Teachers College Record, 104(3), 482-515.

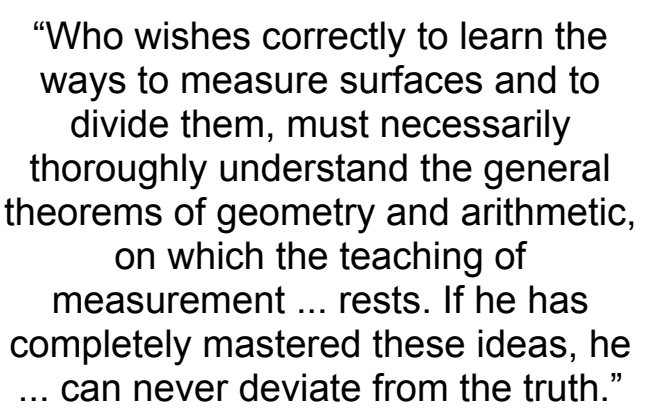

Abraham bar Hiyya 